\title{
The Need of Computer Modelling and Simulation (CMS) Competency among Employers in Malaysia
}

\author{
Mohd Zulhilmi P. Ismadi ${ }^{1}$, Jundika C. Kurnia ${ }^{1 *}$, Shaharin A. Sulaiman ${ }^{1}$, Suhaimi Hassan ${ }^{l}$, \\ Mokhtar Awang ${ }^{l}$, Puteri S.M.M. Yusoff ${ }^{l}$, Alfonso Urquia ${ }^{2}$ \\ ${ }^{1}$ Department of Mechanical Engineering, Universiti Teknologi PETRONAS, 32610 Seri Iskandar, \\ Perak, MALAYSIA \\ ${ }^{2}$ Departamento de Informatica y Automatica, UNED, Juan del Rosal 16, 28040 Madrid, SPAIN.
}

\begin{abstract}
With the continuous improvement in Computer Modelling and Simulation Environment (CMSE) applications being made, computer modelling and simulation (CMS) is proven a better alternative as opposed to conventional physical modelling. The advancement of computing hardware allows accurate results to be obtained faster, safer and at a fraction of its original cost. Despite the proven advantages, CMSE adoption among companies may be fairly new in Malaysia. This study is aimed at quantifying the demand of CMSE specialists in Malaysia as well as gaining insights in the companies' requirements of specialists' knowledge, competencies and skills. Thus, a survey, consisted of 3 main parts, was conducted among industries in Malaysia as a tool of measurement of the demand. The survey included questions related to the general information of the organization, specialists' competencies relation to the job scope, and finally the professional and educational standards among specialists. In general, it was found that practically-competent specialists in CMSE are in high demand among engineering companies. Furthermore, professional courses through distance learning would be of high interest among companies to send their employees to gain practical competency in CMSE.
\end{abstract}

\section{Introduction}

The integration of technology in teaching and learning activities is gaining popularity in education providers. The rapid technological advancement results in increasing affordability and access to technological devices among students, thus allowing the creation of twentyfirst century classroom. This effort is aimed at improving students' learning environment and experience through highly-engaging activities [1]. The use of computers and software in Science, Technology, Engineering and Mathematics (STEM) education have started many years ago. The use of computer tools and software to aid analyses is widely used in STEM especially in medical, engineering, mathematics, materials, chemistry and many other disciplines.

\footnotetext{
*Corresponding author: jundika.kurnia@utp.edu.my
} 
By utilizing mathematical model, tools and simulation, users have access to the expected outcome of their experimentations, given that their model is accurately validated. Additionally, the use of software is proven to be more advantageous, efficient and costeffective in the long run, making it highly attractive in industries [2]. By using a specific software, the process of building physical experimental model for testing can be eliminated. The aforementioned advantage allows strategic decision to be made early, giving the respective team an edge in the competitive market. Furthermore, the improving efficiency, computing power and its architectural design, highly complex models can be simulated within accepted accuracy at a fraction of the time. As more research ventures into this area, a new discipline emerges, known as Computer Modelling and Simulation.

\section{Methodology}

A survey was done specifically among mechanical and marine engineering companies in Malaysia through online platform. Questionnaires were distributed at random to a mixture of large and small engineering companies all over Malaysia. The target respondents were top management of the respective companies. The respondents' information was kept confidential and used for demographic purposes only. The surveys consisted of 3 main components. The first part of the survey asked the general information that targets the organization leaders. This part analyses the needs, salary scale and willingness of companies to train their workers to gain CMS competency. The second component includes questions related to competency distribution within the job scope of the specialist in each organization. Finally, the last and main component of the questionnaires is on the general information and issues in organization that relates to the qualification requirements, education standard in computer modelling as well as professional standards compliance.

\section{Results and Discussion}

Part 1 - Needs and willingness to train employees in CMSE

This component of the survey is aimed at quantifying the size of the organisations as well as quantifying the willingness of the companies to adopt new technologies and gain CMSE specialists. The participants of the survey consisted of $22.7 \%$ of large company (more than 100 employees), $9.1 \%$ of medium sized (up to 100 employees) and $68.2 \%$ of small companies (up to 20 employees). Out of these numbers, only $9.5 \%$ responded that they have more than 50 specialists in the company while the remaining respondents have only less than 20 specialists in their organization. As illustrated in Figure 1, in terms of the implementation of new technologies related to computer modelling, majority of the response $(54.5 \%)$ plan to implement new technologies that require related specialist, $27.3 \%$ plan to implement new technologies that does not require specialists and the remaining $18.2 \%$ of respondents did not have any plan to implement new technologies in the market. Most companies prefer that the specialists in CMSE to possess Bachelor degree qualification compared to higher qualifications such as Master (40.9\%) and doctoral degree (0\%). Due to this reason, $81 \%$ of the responses showed interest for CMSE training or professional development that includes distance learning mode. This results show that most organizations prefer to train and enhance their employees' CMSE competency in oppose to hiring new specialists. 


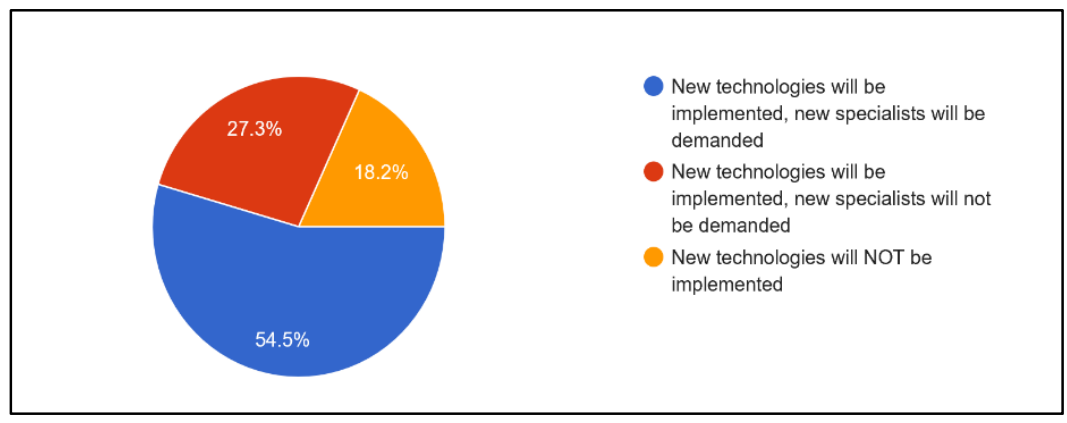

Fig. 1. New technology adoption willingness among industries

\section{Part 2 - Competency distribution in organization}

The second part of the survey determines the softwares and type of CMS applications used by the participating organisations. The outcome of the survey showed that the specialists were able to either operate or both operate and develop equally at $42.9 \%$ each, whereas the remainder were focused on model development. Experimentation of various model and software is the most prominent method among companies at $47.6 \%$, followed by probabilistic models at $23.8 \%$. On the other hand, deterministic models based on Partial Differential Equation (PDE) and Ordinary Differential Equation (ODE) accounted for 19\% and 9.5\%, respectively, as shown in Figure 2.

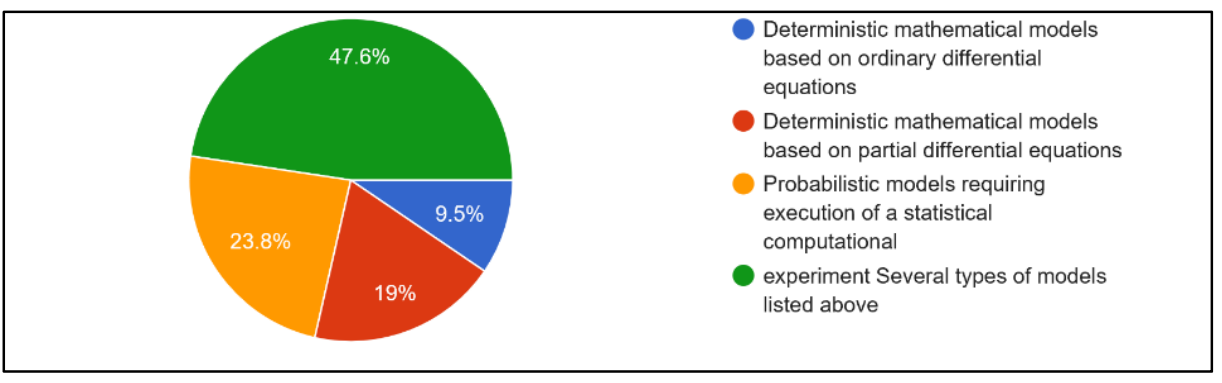

Fig. 2. Specialists profile activities

As expected in the industry, Figure 3 shows majority of the companies (52.4\%) utilize commercially available software packages for their CMS work. 33.3\% matches multiple models and packages and high level algorithmic model development took account the least at $14.3 \%$. This result is expected considering the fast-paced progress in the industry is the most desirable which makes developing model through fundamental programming from a scratch the least popular option. Similar scenario is also reflected when the companies are asked about the specialists they need. Specialists with the ability to develop model are the least desirable (19\%) compared to specialists in applied (23.8\%) and operation $(57.1 \%)$ domains. 


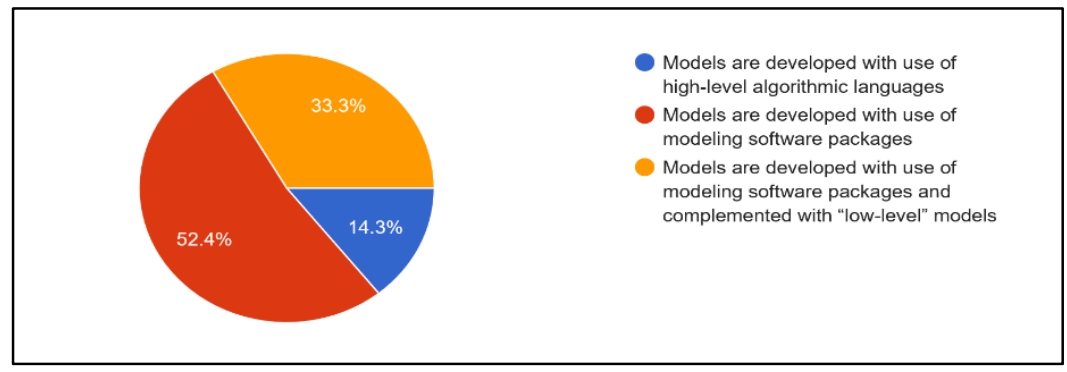

Fig. 3. Types of models used by the specialists in the industy

Part 3 - Qualification requirements, education standard and professional standard

This section quantifies the general issues related to education and professional standard among specialists in each organization. Overall, half of the respondents partially comply to the professional standards whereas $45 \%$ and $5 \%$ fully comply or compliance is insufficient, correspondingly. In a scale of 5, the survey showed that companies favour practical training as opposed to theoretical training with $90 \%$ rated 3 and higher on the former and $85 \%$ on the latter. The survey results showed a cumulative of $80 \%$ responses have some and large interest in university collaboration for practice-oriented process of specialist training program as depicted in Figure 4. The remaining stated either no interest (15\%) or the companies have an in-house department or laboratories that responsible in developing competencies among the specialists $(5 \%)$.

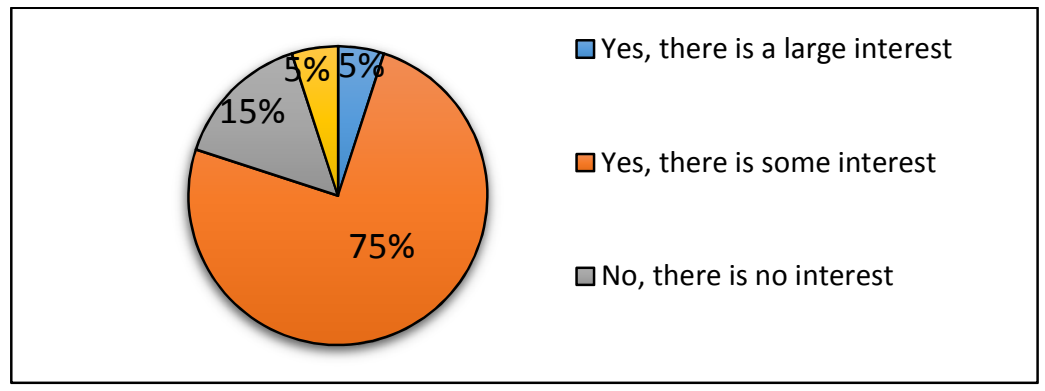

Fig. 4. Academia-industry partnership interest

The questionnaire also quantifies the degree of importance of various personal qualities for a specialist in computer modelling. Most employers responded positively and results showed a consistent scoring of 3 and above in most personal attributes. 50\% employers rated 4 out of 5 in 'personal initiative' and 'ability to work independently' attributes. $10 \%$ and $20 \%$ of employers also scored 5 for the corresponding qualities, separately. Employers also value teamwork and communication skills highly with cumulative $80 \%$ and $70 \%$ scored 4 and higher. Despite that, one respondent rated 2 for both skills. Employers also valued the abilities to solve non-standard problems and adapt to changing conditions highly with a total of $95 \%$ scored 3 and above in both skills. Additionally, self-readiness for further learning among specialists is one of the most defining qualities among employers with the highest distribution at level 4 (45\%) followed by level 3 and 5 at $25 \%$ each. In short, self-awareness and willingness to learn are the deterministic factors for the employees to undergo further learning to enhance their knowledge and competency. The survey also studied the 
expectation of employers on specialists' ability to work in international context. Majority of employers are neutral with $45 \%$ voted 3 and $40 \%$ voted 4 . The results also showed high appreciation to analyse information and critical thinking skills with $20 \%$ voted 3,65\% voted 4 and remaining $15 \%$ voted 5 for both qualities. Summary of results is tabulated in Table 1.

Table 1. Summary of desired specialists' personal qualities.

\begin{tabular}{|l|l|}
\hline Personal qualities & $\begin{array}{l}\text { Highest Level of } \\
\text { importance } \\
\text { (score out of 5) }\end{array}$ \\
\hline Degree of initiative & $3-4$ \\
\hline Ability to work individually, independently from others & $3-4$ \\
\hline Ability to work collectively, in a team & 4 \\
\hline Ability to communicate with non -specialist & 4 \\
\hline Ability of effectively present results of their activities & 4 \\
\hline Ability to solve non-standard problems & $3-4$ \\
\hline Ability to adapt to changing conditions & 4 \\
\hline Readiness for further learning & 4 \\
\hline Ability to work in an international context & $3-4$ \\
\hline Ability to find and analyse information & 4 \\
\hline Ability to think critically & 4 \\
\hline
\end{tabular}

The respondents were also asked a series of question related to the importance of practical competencies for a CMS specialist, as summarized in Table 2. Majority of the employers scored highly in one's ability to understand the principles of quality evaluation, control and management; apply principles of innovative management; collect information from various sources; and apply main methods and procedures of marketing, with at least $65 \%$ of the employers scored 4 and higher in each category. Other traits such as research skill, awareness of recent scientific progression, foreign language command, project development and management were rated averagely important (score 3) among participating companies.

Table 2: Summary of desired specialists' practical competencies.

\begin{tabular}{|l|l|}
\hline Practical Competencies & $\begin{array}{l}\text { Highest Level of } \\
\text { importance } \\
\text { (score out of 5) }\end{array}$ \\
\hline Research competencies & $3-4$ \\
\hline $\begin{array}{l}\text { Awareness of the most recent scientific and technical } \\
\text { achievements in the field of computer modelling }\end{array}$ & $3-4$ \\
\hline $\begin{array}{l}\text { Knowledge and competence in using methods of } \\
\text { mathematical modelling }\end{array}$ & 4 \\
\hline $\begin{array}{l}\text { Collecting information from primary and secondary } \\
\text { sources including internet search }\end{array}$ & 4 \\
\hline Command of foreign language & 3 \\
\hline Project development and management & 3 \\
\hline Leadership skills & 4 \\
\hline $\begin{array}{l}\text { Understanding of the principles of quality evaluation, } \\
\text { control and management }\end{array}$ & 4 \\
\hline Ability to apply principles of innovative management & 4 \\
\hline $\begin{array}{l}\text { Knowledge of the main methods and procedures of } \\
\text { marketing }\end{array}$ & 4 \\
\hline Skills in staff management & $3-4$ \\
\hline
\end{tabular}




\section{Conclusion}

This study highlights the needs of CMS as well as the desired qualities of specialists among employers in Malaysia. Overall, the results of the survey show that the economic environment has the supporting role in facilitating engineering industry to move forward through the integration of technologies in CMS area. More than $80 \%$ of the companies will install new technology that involve new specialists. In terms of training, focus should be given to the operation of models created specifically based customer requirements and needs. This includes highly customizable generic packages such as MATLAB and its embedded toolboxes, as well as other software packages such as Mathematica, Maple and MathCAD. Majority of the employers prefer specialists with either bachelor or master degree qualification. With the increasing demand of CMSE experts, as consequence to technological advancement and compliance requirement to international accords, the institutions of higher learning are tasked with responsibility to ensure that the graduates are instilled with CMS competency through the embedment of CMS components in the syllabus. Furthermore, future prospect includes retraining and further professional courses for qualifying hired employees to be specialists in their respective workplace. The survey also showed that despite the importance of theoretical knowledge, other qualities are also highly expected among the employers. Skills in management, innovation, information gathering as well as quality evaluation are equally important in the industry.

The authors acknowledge funding from the Erasmus Programme of the European Union (Grant Number: 573751-EPP-1-2016-1-DE-EPPKA2-CBHE-JP)

\section{References}

1. A. Hofstein., \& V. N. Lunetta, Science Education, 88(1), 28-54 (2004)

2. H. Shen, Z. Xu, M. S. Shur, V. Kristansen, O. Storm, T. A. Fjeldly, T. Ytterdal, Conducting Laboratory Experiments over the Internet. IEEE Trans Educ E, 42, 180185 (1999). 